\title{
The Settlement Behavior of Granular Soils Under Vertical Loading Using the Histogram Equalization Method
}

\author{
Can Erenson \\ Civil Engineering Department, Engineering Faculty, Aksaray University, Aksaray, Turkey
}

Corresponding Author: canerenson@aksaray.edu.tr

Submitted: 06-12-2020

Revised: $15-10-2021$

Accepted: 26-10-2021

\begin{abstract}
Settlement characteristics of soils are an important phenomenon in terms of bearing capacity and failure behavior. Within this context, the relative density value is a significant factor but its correlations are insufficient to provide precise results under exceptional conditions. The main aim of this study is to determine, for each soil type, the parameters that affect the settlement behavior of granular soils. Soil samples belonging to different granular soil classes were placed in transparent boxes and monitored. Then, behaviors were determined using the Histogram Equalization Method (HEM) performed on the images and loading tests. As a result, it was observed that relative density was the most effective factor for settlement behavior in sandy soils. Also, well-grading criteria was the most important factor for gravelly soils in their settlement behavior. In the well-graded soil samples in a dense condition, the pixel numbers in the image were found to be approximately 2 times higher than in the loose soils. On the other hand, the maximum pixel number for loose conditions in poor-graded soil samples was determined between 1.02 and 1.17 times greater compared to the dense soils. Consequently, the outputs obtained from the HEM agreed with the experiments.
\end{abstract}

Keywords: Gradation; Granular soil; Histogram equalization method; Settlemen

\section{INTRODUCTION}

With the development of technology, image processing techniques are widely used in engineering fields in many different ways; structural monitoring, damage and behavior assessment, identification, and evaluation. Determining the behavior of the materials and structures formed by the elements is of great importance in terms of service life, functionally, cost, maintaining support services, and most importantly safety criteria. Therefore, the material properties must be well determined initially and they must be compatible with each other. In addition, to determining the engineering properties of soils, it is an important issue to reflect the relationship between the grains, bearing capacity, settlement, collapse modes, etc. Apart from laboratory and field tests, imaging techniques and ultrasonic methods have been among the popular methods to determine behavior in recent times. Among these methods, the best-known methods for determining soil structure and behavior are computer tomography (CT), scanning electron microscopy (SEM), ultrasonic non-destructive testing (UNDT), structural health monitoring (SHM), and digital image processing (DIP). Ideal imaging or wavelength-based methods should be chosen to determine the formal characteristics of the materials according to the field of application. In this respect, it is necessary to define the properties of different types of materials based on many criteria in the study to evaluate the data analysis precisely. Due to the physical structure of the grains, the effect of the compactness of the granular soils under different conditions on their behavior directly affects the failure mechanisms. DIP, one of the most widely used techniques, is based on examining the data pattern of the images obtained with high-resolution cameras and evaluating the collected digital pattern. DIP is used in many fields such as the health sector, space technologies, agriculture, and food as well as in determining the soil characteristics in the field of geotechnics. RGB (red, green, blue) and grayscale-based images are supported by analytical calculation methods and provide data on material profiles. There are many important studies in the literature on the exploration of material texture and texture-based behavior. In the examination of material deformation characteristics, cross-sectional images have been analyzed and interpreted with numerous imaging, photographic editing, and development techniques in 
recent years. Zhao and Zhou (2019) conducted digital measurements of the cracks observed in sandstones using the improved pseudo color image enhancement and 3D reconstruction. Pires et al. (2011) conducted studies on wetting-drying (W-D) cycles using gamma-ray CT scanning of clayey soil samples and examined the porositysoil bulk density relationships. In another study, the mechanical behavior of volcanic coarse-grained soil exposed to seepage flow was investigated using Digital Image Correlation (Hieu et al., 2017).

In addition to determining the engineering properties of soils, many studies in the literature have focused on examining the superficial or internal structures of materials. There are studies within the scope of investigation of soils using imaging techniques, pixel mapping using Matlab to determine the macroporous structure Tekin et al. (2015), and classification using hue, saturation, and value (HSV) histograms of the images for percentage calculations of sand, silt and clay Barman and Choudhury (2020) in the literature. The use of imaging techniques is very popular in soil classification. Recently, it is known that new methods such as deep learning (Srivatsa et al., 2021) and wavelet model (Shivhare and Cecil, 2021) have been developed using imaging techniques.

The definition of relative density was created to clearly express the compaction of cohesionless soils as equivalent under all conditions. There is a considerable amount of study to indicate the unreliability of this description due to its fallibility. Hamidi et al. (2013) emphasized that there is great inaccuracy associated with relative density correlations. Although the relative density value of the soil is a parameter that can give an idea of its bearing capacity and collapse behavior, there are also times when it is insufficient to provide definitive individual results. In these circumstances, swelling, loosening, and undulations occurring at a specific load on the soil surface can change the soil behavior.

There are many methods for the classification and description of soil behavior. Using imaging techniques while making these distinctions provides access to data in a modern, fast, and most importantly non-destructive manner. However, studies on the determination of soil texture and the local distribution of grains under vertical loading are rarely seen in the literature. In this study, the behavior of silica sand, river sand, sandy gravel aggregates, and basalt aggregates placed under different density conditions in a transparent box was examined by imaging with a high-resolution camera. As a result of the definitions made concerning the Matlab outputs, the settlements of granular soils under vertical loading were interpreted by matching them with histogram analysis.

The HEM is a widely used technique for image contrast adjustment using the image histogram (Arısoy and Dikmen, 2014). This method increases the contrast values of those regions of an image reflected by low contrast values. As a result of this adjustment, the brightness values of the image show a better distribution on the image histogram. Thus, the visibility of inconspicuous regions is increased and the image interpretation is better. The HEM is preferred in many different areas because of its low computation time and effective results. There are many studies in the literature on the algorithms and digital image applications of the HEM (Gonzales and Woods, 2008; Russ, 2011). Also, it is possible to examine settlement problems more comprehensively using probabilistic analysis (Bungenstab and Bicalho, 2016), reliability analysis (Wang et al., 2013), simplified methods (Li, 2014), etc. Alternatively, the use of the HEM in the settlement analysis of granular soils brings along significant improvements.

In this study, the settlement behavior of granular soils was investigated using the HEM, which achieved successful solutions in the characterization processes with its advantageous features in many different areas. As a result of the HEM outputs, the effects of engineering parameters of granular soils on settlement were associated with the intensity values of grain-based texture formation. Additionally, it has been emphasized that the characteristics of the compaction process should be examined in the planned calculations regarding the relative density value. Thus, it has been stated that the HEM can be used in behavior analysis such as settlement, and an alternative method was developed to achieve more realistic results by emphasizing the characterization of relative density-related inconsistencies. The original aspect of the study is to determine the load-dependent behavioral change of many physical properties of granular soils in different classes with HEM. Briefly, the engineering properties of granular soils were investigated with a new method. Finally, which criteria was more effective for each granular soil type in the load-settlement behavior was visually and experimentally examined and interpreted. 


\section{MATERIALS}

\section{Particle distribution and classification}

In the evaluation of granular soils, silica sand and river sand were selected as variables because of their uniform distribution condition. Accordingly, silica sand and river sand represented uniform conditions. The variables among the aggregates were evaluated in terms of grain size and porous structure. The investigated granular soil types are given in Figure 1.

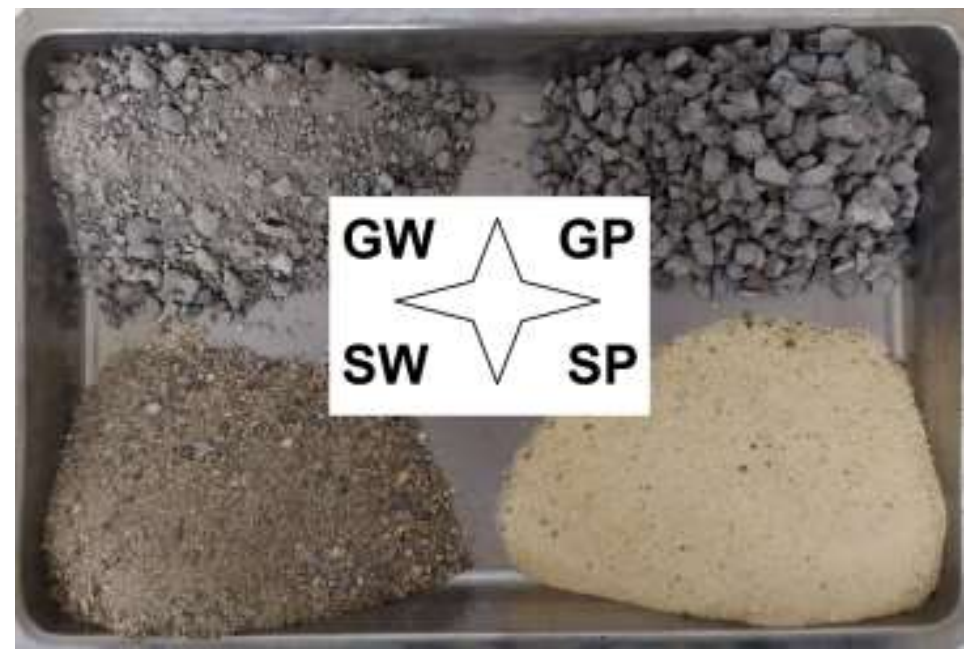

Figure 1. Granular soil types classified according to the Unified Soil Classification System

This study investigated the settling and particle distribution behaviors of different classes of granular soils under a vertical load. Two different criteria were taken into account in the selection of variables in terms of the importance of uniformity, grain distribution, compactness, and stress effects. Silica sand and basalt aggregates represented uniformity and poor grading, while river sand and sandy gravel aggregates represented uniform distribution and well grading. Classifications were evaluated according to the Unified Soil Classification System (ASTM D2487-17, 2011).

\section{Silica sand (SP)}

Washing, enrichment, classification, and dewatering processes were carried out in the production of pure and uniformly distributed silica sand. The sand produced by the supplier was untouched by human hands with a maximum AFS clay of $0.5 \%$, a maximum humidity of $7 \%$, and a degree of homogeneity of $70 \%$ or above (Siltas, 2018). According to the sieve analysis, the sample contained $0.2 \%$ clay and silt, $99.8 \%$ sand. As a result of the sieve analysis, the tested soil class was determined to be poorly graded sand (SP).

\section{River sand (SW)}

The river sand was sampled in the Kirsehir area, which is located near Ankara, in the center of Turkey. The river sand was classified as well-graded sand (SW), of which the coefficient of uniformity was 6.8 , and the coefficient of curvature was 2.7. According to the sieve analysis, the sample contained $2.4 \%$ clay and silt, $97.6 \%$ sand. As a result of the sieve analysis, the tested soil class was determined to be well-graded sand (SW).

\section{Basalt aggregates (GP)}

Basalt aggregates were sampled from Hasandagi Mountain, which is located between Nigde and Aksaray, in the center of Turkey. Basalt aggregates were classified as poorly graded gravel (GP), of which the coefficient of uniformity was 3.2 and the coefficient of curvature was 0.9. According to the sieve analysis, the sample contained $2.2 \%$ clay and silt, $95.2 \%$ sand, and $2.6 \%$ gravel. As a result of the sieve analysis, the tested soil class was determined to be poorly graded gravel (GP). 


\section{Sandy gravel aggregates $(\mathrm{GW})$}

Sandy gravel aggregates were sampled from the Aksaray region, which is located in the center of Turkey. Sandy gravel aggregates were classified as well-graded gravel (GW), which had a coefficient of uniformity of 13.2 and a coefficient of curvature of 2.7. According to the sieve analysis, the sample contained $3.4 \%$ clay and silt, $48.2 \%$ sand, and $48.4 \%$ gravel. As a result of the sieve analysis, the tested soil class was determined to be wellgraded gravel $(\mathrm{GW})$.

\section{Determining the engineering properties of granular soils}

\section{Relative density}

Relative density values were obtained based on sample weights in a box under constant volume conditions for each sample. The reference values according to the weights determined for the loosest and densest conditions were calculated to within a 5\% range for each soil. In the study, the relative density values associated with other engineering properties were graphically reflected with this calculation method. For all experiments, samples were prepared by considering the above-mentioned volume-weight correlations.

\section{Void ratio}

In the experiments, a test box was used to determine the void ratio values of the specified density ranges. The highest void ratio values for each granular soil type were found by allowing from a cone placed at a constant height. To achieve the lowest void ratio the soil was compacted by a $5 \mathrm{~kg}$ rammer falling at a distance of $250 \mathrm{~mm}$ into a soil-filled mold. The mold was filled with six layers of soil and each layer was subjected to 15 blows from the rammer. Then, void ratio values were determined by reference to the weights corresponding to each relative density value. The samples dried in the oven were filled using cones following the ASTM D698 (2012) for each soil type.

\section{Internal friction angle}

The internal friction angle parameters of granular soils were determined by consolidated undrained (CU) triaxial tests according to TS 1900-2 (2006). In these tests, relative density - void ratio and relative density - weight per unit of volume value controls were checked to prepare samples with variable density values. Three samples were tested for each relative density condition and the average values from two control processes were evaluated. Relative density checks were carried out by weighing each sample. Triaxial pressure tests were carried out by applying $100 \mathrm{kPa}$ and $200 \mathrm{kPa}$ cell pressures to prepared samples with a diameter of $50 \mathrm{~mm}$ and a height range from 107 to $111 \mathrm{~mm}$.

\section{Elasticity modulus}

This study also examined the effect of relative density on the engineering properties of cohesionless soils such as shear strength parameters, void characteristics, elasticity modulus, etc. Soil elasticity modulus (E) is an elastic soil parameter widely used in the estimation of settlement caused by static loads. Laboratory tests that can be used to estimate the soil elasticity modulus are the triaxial compression tests (Kulhawy and Mayne, 1990; Geotechdata, 2013). In determining the elasticity modulus evaluated in the study, given that cohesionless soils were examined, the CU test (TS 1900-2, 2006) and empirical approaches were used as a result of a literature survey (Obrzud and Truty, 2018; Carter and Bentley, 2016; Ameratunga et al., 2016).

\section{Unit weight}

Dry samples were weighed before the vertical loading and imaging process. For each relative density value, the weight value was proportional to the test box volume and unit weight values were calculated as in Equation 1. These values are also compatible with the void ratio calculation as shown in Equation 2 (Atkinson, 2007). These equations are expressed as: 
where $\gamma$ is the unit weight $\left(\mathrm{kN} / \mathrm{m}^{3}\right), \mathrm{W}$ is the weight $(\mathrm{kN}), \mathrm{V}$ is the volume $\left(\mathrm{m}^{3}\right)$, e is the void ratio, $\mathrm{V}_{\mathrm{V}}$ is the volume of voids $\left(\mathrm{m}^{3}\right)$ and $\mathrm{V}_{\mathrm{S}}$ is the volume of solids $\left(\mathrm{m}^{3}\right)$.

\section{METHOD AND TESTING PROCEDURE}

The testing procedure consisted of five main steps: preparing granular soil samples, compacting the samples in accordance with relative density, loading in increments, acquiring images of digital image analysis techniques, and an evaluation of the data.

Initially, the silica sand was placed in a transparent glass box $\left(300 \times 200 \times 120 \mathrm{~mm}^{3}\right)$ using a cone to ensure uniformity in each of the experiments. After the filling process, for each test, the specimen was weighed, and the relative density conditions were checked. Density checks were performed according to the index properties calculation of the weighed specimens. At this stage, it was of great importance that the soil from every region was filled to an equivalent level. Oven-dried granular materials were filled using a cone having a nozzle about $12 \mathrm{~mm}$ in diameter. The granular soil grains were spread in the forming mold with a zero level of fall at a constant velocity until the mold became filled with the dry grains. Ishihara (1996) emphasized that the load energy was applied by hitting the side of the mold to obtain the desired density condition. Even so, despite the maximum attention paid to both the filling and weighing processes, Ishihara stated that it was not sufficient for sample preparation due to the various characteristics regarding relative density. In this study, the correlations between these uncertain characteristics and the relative density conditions from image-oriented interpretations were further examined by histogram analysis.

A circular loading plate with a diameter of $5 \mathrm{~cm}$ was positioned in the middle of the test box. Then, the load was applied by the testing machine through a data logger and adjusted to the connected interface at a crosshead speed of $10 \mathrm{~mm} /$ minute. The pattern created by the stress occurring under $\mathrm{K}_{0}$ conditions on the glass edge surface was recorded with a high-resolution camera. With final preparations completed, images of the movements observed on the glass surface were captured. As a result, the collected images were interpreted by comparing the engineering properties of granular soils.

\section{Histogram equalization method (HEM)}

An image histogram is a graph that describes the number of color values in the image. In a grayscale image, each pixel represents a brightness value between 0 and 255 . The brightness value of black and white are 0 and 1 , respectively. However, the histogram of a grayscale image shows the number of pixels of various values of brightness across the range from 0 to 255 . In the histogram graph, the left side represents the darkness and the right side represents the brightness. Color distribution in a certain region in the image histogram means the contrast is low. Conversely, a balanced distribution of color values indicates that the contrast is high. There are many image processing techniques for increasing low contrast images and the most commonly used method is histogram equalization. Histogram equalization eliminates the color distortion caused by the clustering of color values in a certain region. Short calculation time and efficiency are the advantages of this method. Regarding the assumption that any digital image is represented by " $\mathrm{f}$ " and the amplitude values of each pixel of this image vary between 0 and L-1. Here, L indicates the total number of possible amplitude values in the image, and its value for grayscale images is 256. The normalization of the histogram of such an image is as shown in Equation 3 (Shan and Lai, 2019). Here, $P_{f}$ can be determined by

$P_{f}\left(f_{k}\right)=\frac{n_{k}}{n} \quad k=0,1,2, \ldots, L-1$

where $n$ is the total number of pixels, $f_{k}$ is the amplitude value and $n_{k}$ is the number of pixels with $f_{k}$ amplitude.

As a result, the graphic obtained by plotting $\mathrm{P}_{\mathrm{f}}\left(\mathrm{f}_{\mathrm{k}}\right)$ function of $\mathrm{f}_{\mathrm{k}}$ is called an image histogram (Arısoy and Dikmen, 2014). The generalized histogram equalization function $\mathrm{T}$ is given in Equation 4 (Gonzalez and Woods, 2008).

$T\left(f_{k}\right)=\sum_{j=0}^{k} p_{f}\left(f_{j}\right)=\sum_{j=0}^{j=0} \frac{n_{j}}{n} \quad k=0,1,2, \ldots, L-1$

The histogram equalization calculation of a digital image consists of three stages. Initially, the color amplitude value is counted for each pixel in the digital image, and the amplitude index increases by one for the other pixels at an equal amplitude value. Thus, the histogram of the digital image is calculated. In the second step, 
the cumulative distribution function called the cumulative histogram is calculated. In the cumulative histogram, the index assigned to each color value is summed up with the preceding index values. Each value of the cumulative histogram is multiplied by the maximum requested value in the image, and the result is divided by the total number of pixels. Finally, the low contrast problem in the image is eliminated, thanks to the proportional distribution of color amplitudes in the histogram of the digital image.

\section{Imaging process}

Image processing was conducted on a $300 \times 200 \mathrm{~mm}^{2}$ area in front of the test box with high-resolution cameras. The grains, void structures, and layers were examined using the Matlab R2016b program. The images were divided into pixels and the spaces and grains were defined over the RGB values for each pixel. While determining the grains, voids, and layers were first introduced to the program. Then, the differences between the layers that are marked manually on the pictures were determined. Finally, soil types were compared with the test results for loose and dense conditions. The testing equipment is shown in Figure 2.

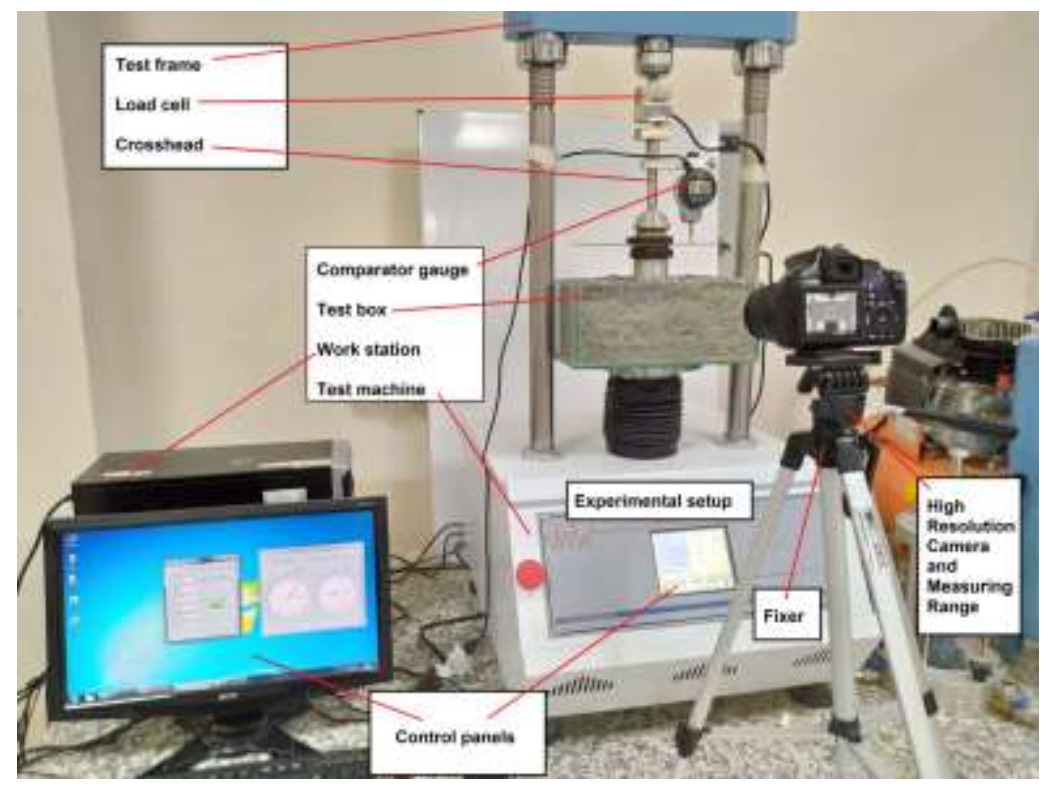

Figure 2. Test frame and testing equipment

\section{TEST RESULTS AND DISCUSSION}

The test results were evaluated in three stages: relative density-engineering property correlations, determination of deformation, and histogram equalization outputs.

\section{Relative density-engineering property correlations}

The graphs made regarding the relative density of soil samples filled and compacted at specified compactness are given in Figures from 3 to 6, for void ratio, internal friction angle, elasticity modulus, and unit weight, respectively. 


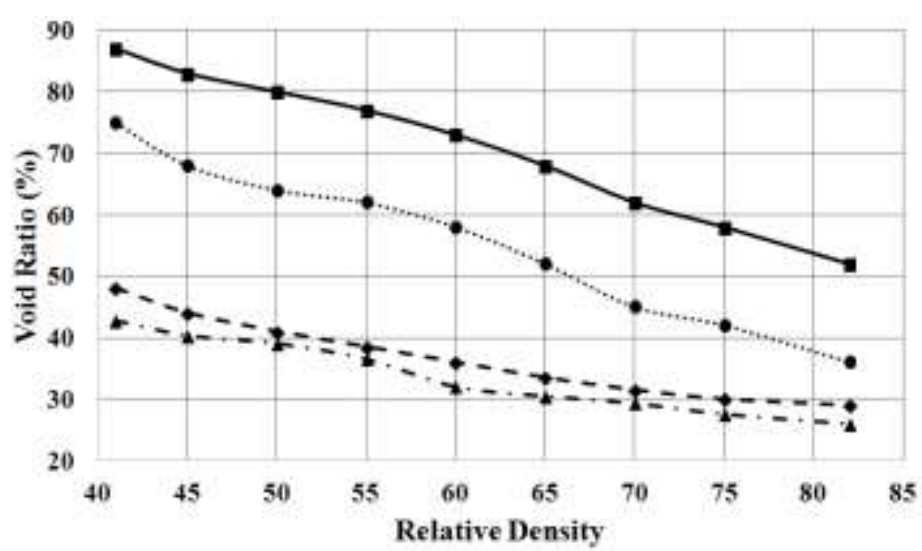

$\rightarrow-\mathrm{SP} \quad \cdots \mathrm{SW} \quad-\star \cdot G W \quad \rightarrow \mathrm{GP}$

Figure 3. Relative density - void ratio graph

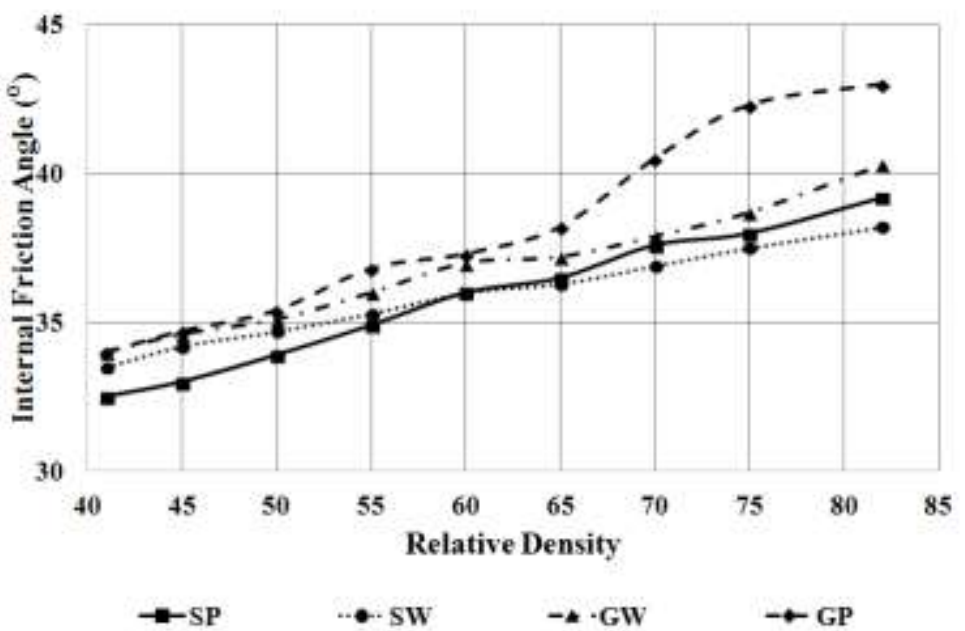

Figure 4. Relative density - internal friction angle graph

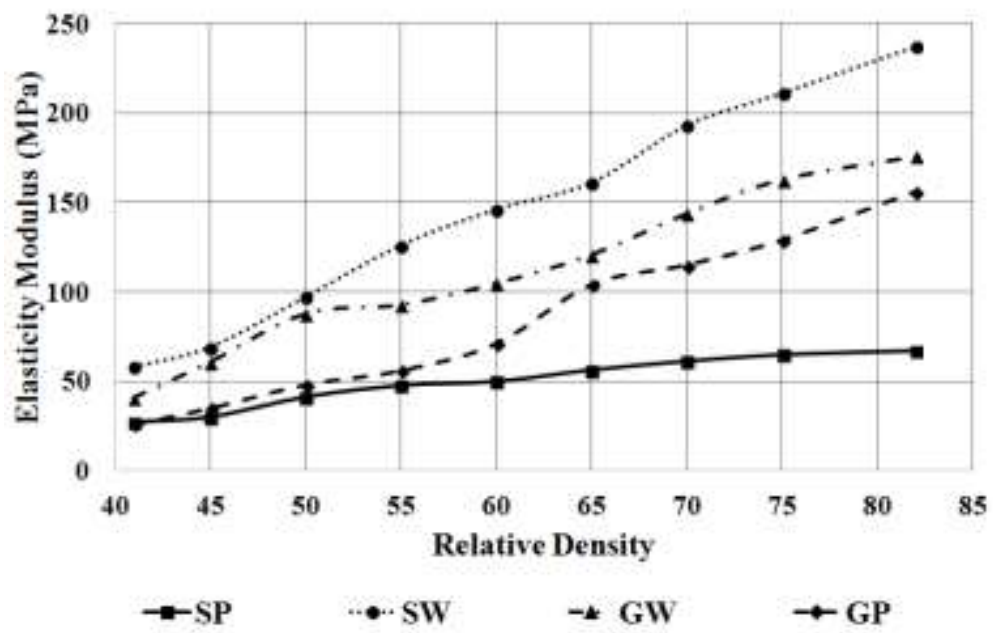

Figure 5. Relative density - elasticity modulus graph 


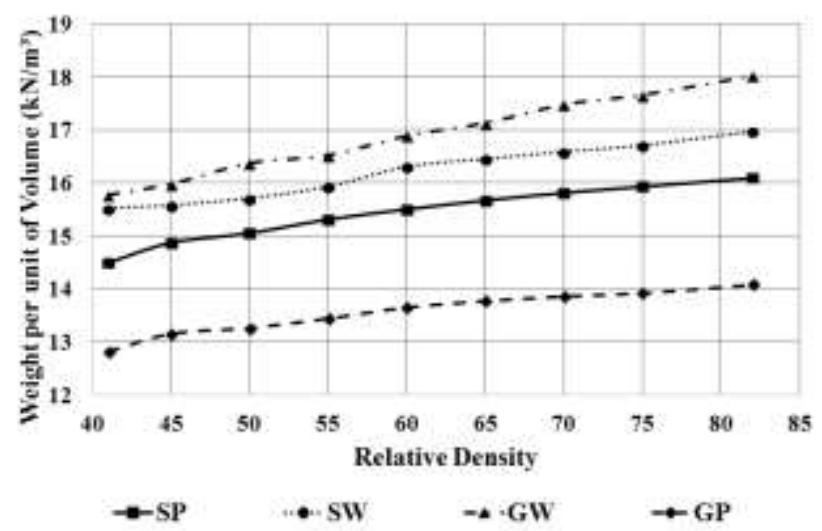

Figure 6. Relative density - unit weight graph

As a result, each s oil sample gave results compatible with the literature and there was no intersecting line in the relative density related-graphs. Providing these conditions is of great importance to the study. Thus, under equal conditions, an additional variable does not change the behavior when interpreting load-settlement graphs and histogram outputs.

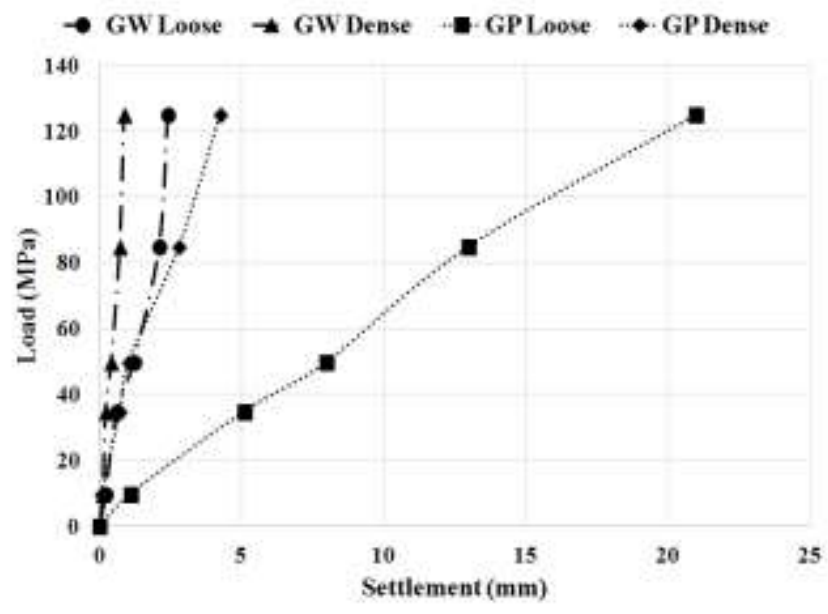

Figure 7. Load - settlement graph for gravelly samples

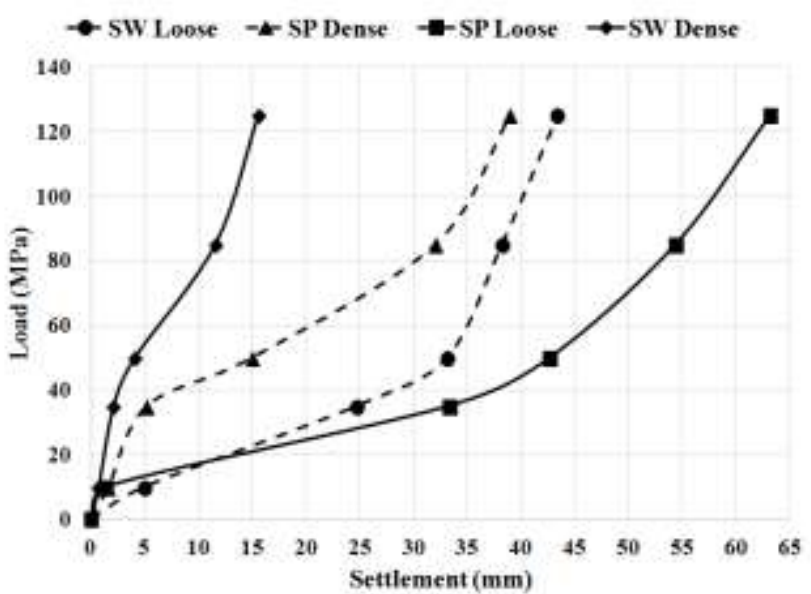

Figure 8. Load - settlement graph for sandy samples 
The compacted GP sample reached a higher settlement value than the loose GW sample. On the other hand, the compacted GW sample showed the lowest settlement among the gravelly samples. In this respect, as a result of the experiments examining gravelly samples, the grading criteria were observed to be a more significant factor.

Among the sandy samples, the loose SW sample settled more than the compacted SP sample. As expected among loose sand samples, the poorly graded sample showed more settlements. Also, among all the sandy samples, the lowest settlement was observed in the compacted SW sample. Therefore, compactness was a more significant factor in sandy samples.

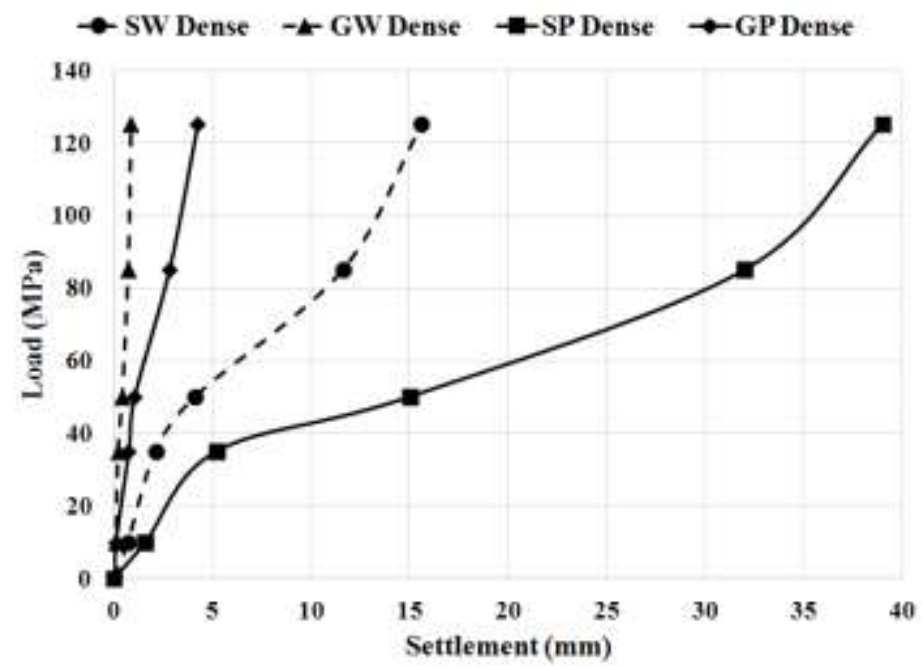

Figure 9. Load - settlement graph for compact samples

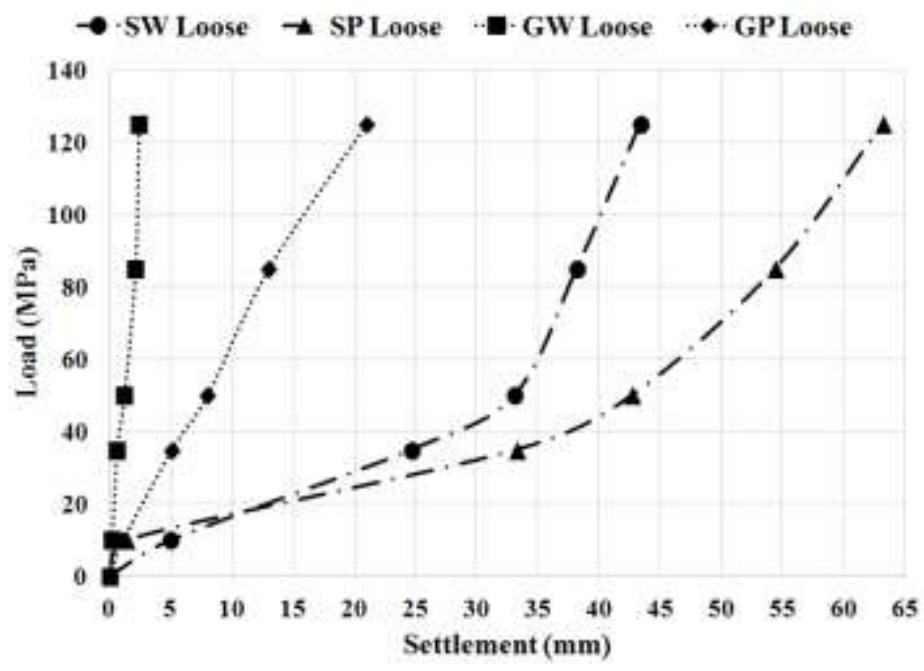

Figure 10. Load - settlement graph for loose samples

Under conditions where the densest and loosest states were evaluated for each sample, the main factor in the settlement was grain size. Roughness and intergranular friction resistance were effective in decreasing settlement. Also, as expected, well-graded sandy and gravelly samples, both in the densest and loosest conditions, showed lower settlement values for the same type of soil than poorly graded samples.

\section{Histogram equalization outputs}

Within the scope of the study, images obtained from the side surface of the glass-box for the densest and loosest soil samples were analyzed by the HEM. In this section, the histogram of the original image was interpreted 
by comparison with the equalized histogram. The color of the material, grain size, particle distribution, void ratio, etc. determined the characteristics of the image on the glass surface created by the material filling. However, this characteristic was related to the pixel density per area in images evaluated in grayscale. The decreasing void ratio under the vertical load effect enabled the dark-colored grains to converge and interlock. Therefore, the density changes, and the histogram of the image became different. Graphs of the original image histograms (OIH) and equalized image histograms (EIH) are given in Figure 11 and Figure 12 for gravelly and sandy soil samples, respectively.

The intensity value range of well-graded gravel and well-graded sandy samples is wider in OIH for loose soil conditions. As the ground is compacted, the image becomes denser in grayscale and a darker image is created. In this case, the intensity value occurs over a narrower range. Well-graded soil samples have a wider intensity range compared to poorly graded soil samples as they provide a low void ratio and high unit weight conditions. Thus, more equalization occurred in the histogram graphs of the GW and SW samples.

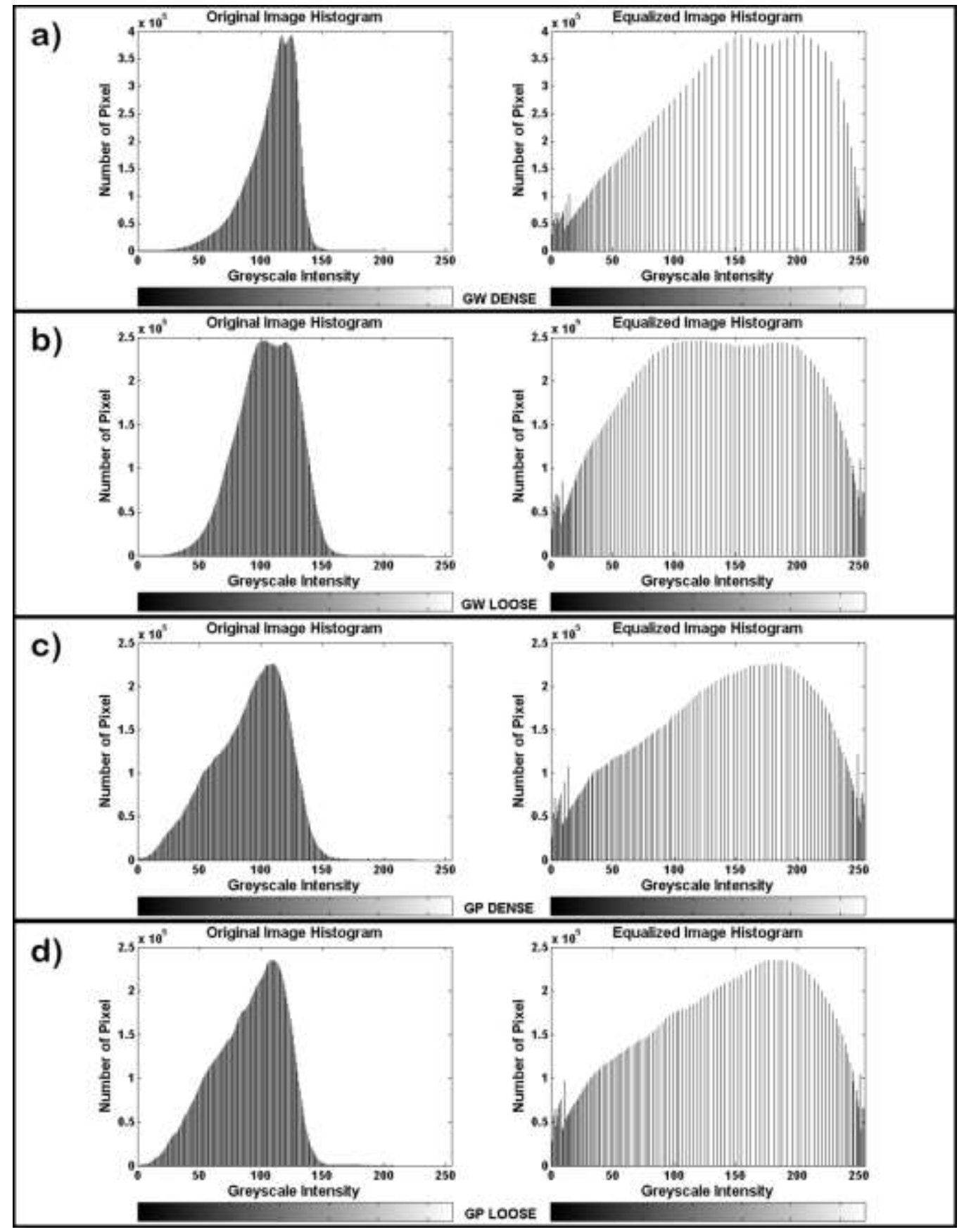

Figure 11. Original and equalized image histograms for gravelly soil samples, (a) GW Dense, (b) GW Loose, (c) GP Dense, (d) GP Loose 


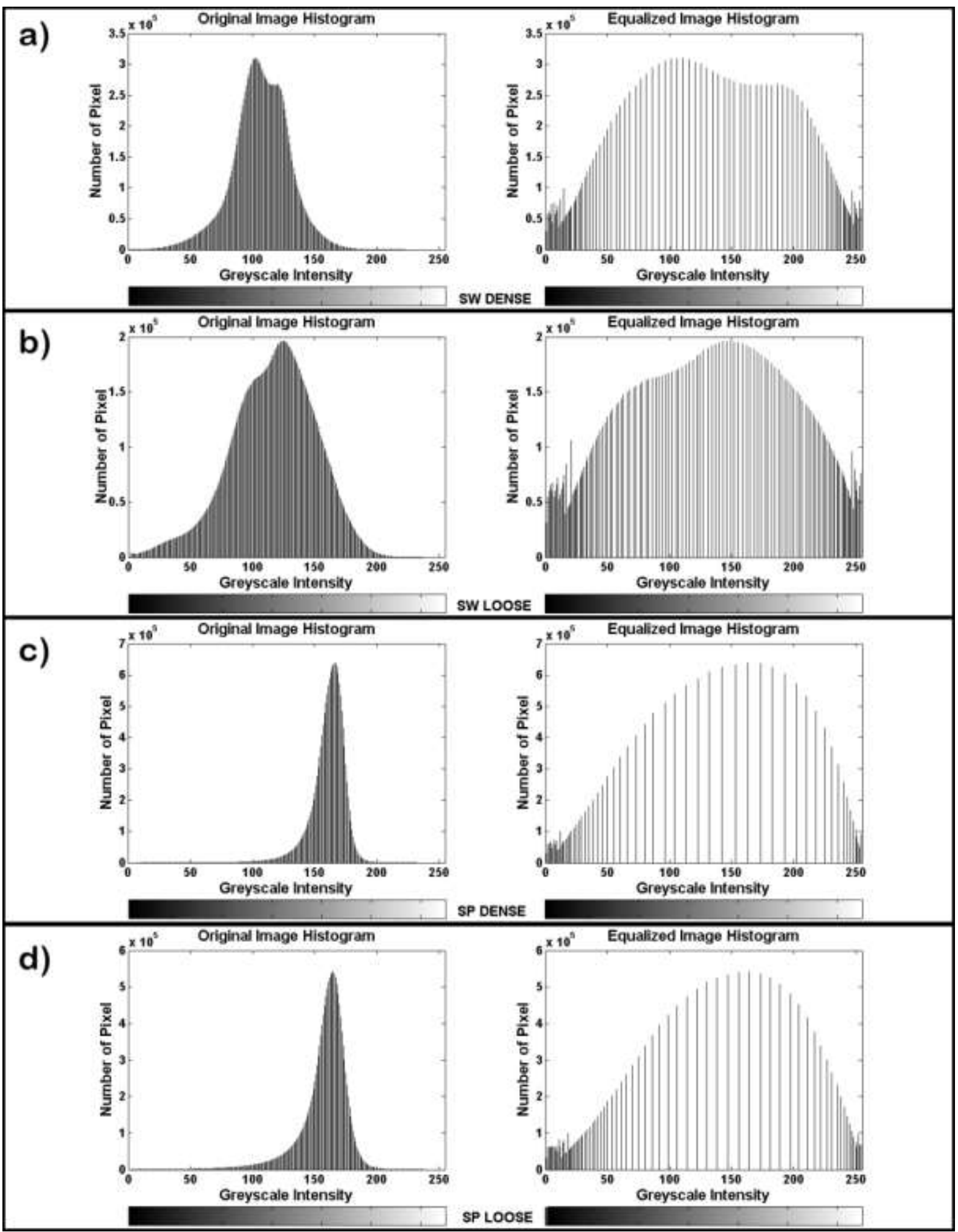

Figure 12. Original and equalized image histograms for sandy soil samples, (a) SW Dense, (b) SW Loose, (c) SP Dense, (d) SP Loose

The difference values in the grayscale intensity ranges were observed to be lower for the well-graded samples since effective compaction could not be achieved for the poorly graded soils. In the well-graded soil samples for the dense condition, the number of pixels in the image was found to be approximately 2 times higher 
compared to the loose soils. On the other hand, the number of pixels for the loose condition in poorly graded soil samples was determined to be between 1.02 and 1.17 times more compared to dense soils. This situation can be explained by the average intensity-number of pixels graph is given in Figure 13. Each line in this graph represents the intensity differences between $\mathrm{OIH}$ and $\mathrm{EIH}$.

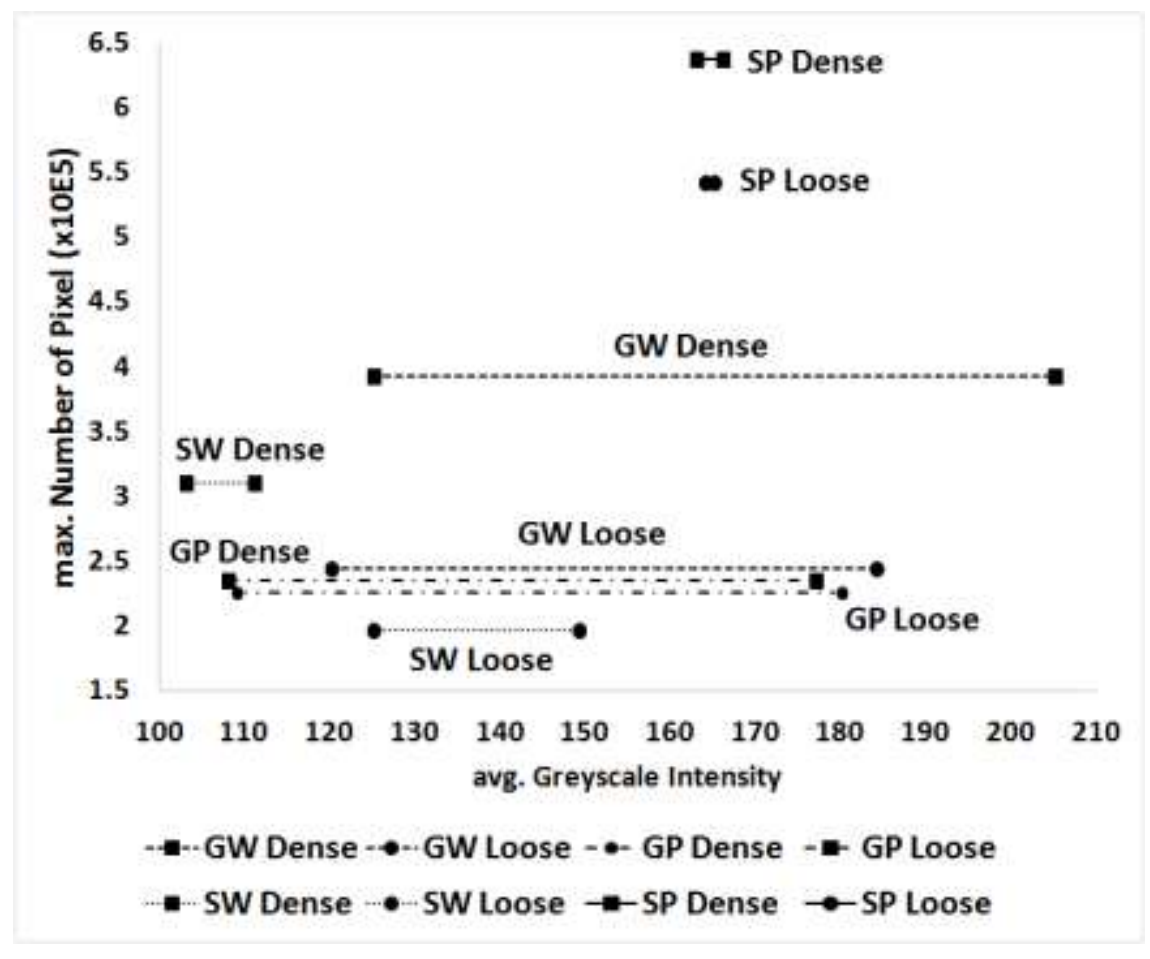

Figure 13. Average greyscale intensity - maximum number of pixels graph

In the outputs of the HEM, SP samples with the highest void ratio values were identified by short lines as they showed the lowest average intensity differences. The high void ratio and poorly graded conditions prevented the compacted structure in the soil texture, so there were no significant changes in the image profiles. Therefore, the average intensity differences in these types of samples were low.

The SW sample had the second-highest void ratio. Due to the larger average intensity differences for well-graded samples, they were represented by a longer line compared to poorly graded ones. In contrast, the gravel samples (GW and GP) with the closest void ratio for each relative density value had similar line lengths. As a result, both the high average grayscale intensity differences and the high maximum number of pixels in the relevant graph indicated the sample with the lowest void ratio.

The low void ratio is of great importance in settlement behavior. In this context, the loosest and poorly graded sample (SP Loose) showed the highest settlement value under the ultimate loading. Then, SW Loose, SP Dense, and SW Dense samples reached the highest settlement values, respectively. This ranking showed that compactness was a more effective parameter in sandy soil samples compared to other factors. In gravelly samples, the well-grading criteria contributed to a more effective factor in settlement behavior. GP Dense and GP Loose samples showed the highest settlement values among gravelly samples. As expected, as a result of the laboratory tests and histogram graphs, the lowest settlement value belonged to the GW Dense sample due to well-grading and a low void ratio value.

\section{CONCLUSIONS}

The engineering properties of a material are effective in calculating the void ratio and these parameters determine the settlement behavior. As seen in Fig. 13, the correlations between OIH-EIH graph data and settlement behavior can be clearly interpreted. In this study, inconsistencies that occur in relative density conditions were highlighted as well as the settlement analysis using the HEM. 
Many kinds of researches and applications have been carried out by only considering the relative density values. However, the settlement should not be considered as showing linear behavior against relative density, otherwise, this situation may cause errors in project, design, and application phases. Relative density graphs can be seen as linear in controlled laboratory experiments but material characteristics may play a more significant role in settlement behavior. Intersections, nonlinear curves, and slopes of variable load-settlement graphs in the settlement charts presented in the study explain this situation. As a result, weight and compression controls may not be sufficient in soil filling to prevent such mistakes. Additionally, the behavior of the index properties of the soil between loosest and densest conditions needs to be well defined by another control method. The outputs obtained from the histogram equalization technique applied in this study agreed with the laboratory experiments demonstrating the load-settlement behavior. It was revealed that the HEM can be used in the classification, identification, and determination of the settlement potential of granular dry soils. Finally, the fact that relative density correlations do not give completely reliable results under all conditions was demonstrated by both the laboratory experiments and the HEM.

\section{ACKNOWLEDGEMENTS}

The research was carried out in the Engineering Faculty's Geotechnical and Computer Laboratories at Aksaray University.

\section{REFERENCES}

ASTM D698. 2012. Standard test methods for laboratory compaction characteristics of soil using standard effort. In: Annual Book of ASTM Standards. Philadelphia (PA), USA.

ASTM D2487-17. 2011. Standard classification of soils for engineering purposes (Unified Soil Classification System). In: Annual Book of ASTM Standards, West Conshohocken, USA.

Ameratunga, J., Sivakugan, N. \& Das, B.M. 2016. Correlations of soil and rock properties in geotechnical engineering. 1st ed. New Delhi: Springer India.

Arısoy, M.Ö. \& Dikmen, Ü. 2014. The improvement of magnetic anomaly maps using histogram equalization method. Bulletin of the Earth Sciences Application and Research Centre of Hacettepe University. 35(2): 175-184.

Atkinson, J. 2017. The Mechanics of Soils and Foundations. 2nd edition, London: CRC Press.

Barman, U. \& Choudhury, R.D. 2020. Soil texture classification using multi class support vector machine. Information Processing in Agriculture. 7(2): 318-332. https://doi.org/10.1016/j.inpa.2019.08.001

Bungenstab, F.C. \& Bicalho, K.V. 2016. Settlement predictions of footings on sands using probabilistic analysis. Journal of Rock Mechanics and Geotechnical Engineering. 8(2): 198-203. https://doi.org/10.1016/j.jrmge.2015.08.009

Carter, M. \& Bentley, S.P. 2016. Soil properties and their correlations. 2nd ed. United Kingdom: John Wiley \& Sons.

Geotechdata. 2013. Soil elastic young modulus. [accessed: 18 September 2020]. Available from: http://www.geotechdata. info/parameter/soil-young's-modulus.html

Gonzales, R.C. \& Woods, R.E. 2008. Digital Image Processing. 3rd ed. New Jersey: Prentice Hall.

Hamidi, B., Varaksin, S. \& Nikraz, H. 2013. Relative density correlations are not reliable criteria. Proceedings of the Institution of Civil Engineers - Ground Improvement. 166(4): 196-208. https://doi.org/10.1680/grim.11.00016

Hieu, D.M., Kawamura, S. \& Matsumura, S. 2017. Internal erosion of volcanic coarse grained soils and its evaluation. International Journal of Geomate. 13(38): 165-172. https://doi.org /10.21660/2017.38.70411

Ishihara, K., 1996. Soil Behaviour in Earthquake Geotechnics. 1st ed. Oxford: Clarendon Press. 
Kulhawy, F.H. \& Mayne, P.W. 1990. Manual on estimating soil properties for foundation design. Palo Alto, CA (USA): Electric Power Research Institution; Ithaca, NY USA: Cornell University; Geotechnical Engineering Group.

Li, C. 2014. A simplified method for prediction of embankment settlement in clays. Journal of Rock Mechanics and Geotechnical Engineering. 6(1): 61-66. https://doi.org/10. 1016/j.jrmge.2013.12.002

Obrzud, R.F. \& Truty, A. 2018. The Hardening Soil Model - A Practical Guidebook Z Soil PC 100701 Report. Edition 2018. Switzerland: Zace Services Ltd. Software Engineering.

Pires, L.F., Cassaro, F.A.M., Bacchi, O.O.S. \& Reichardt, K. 2011. Non-destructive image analysis of soil surface porosity and bulk density dynamics. Radiation Physics and Chemistry. 80(4): 561-566. https://doi.org/10.1016/j.radphyschem.2010.12.006

Russ, J.C. 2011. The image processing handbook. 6th edition, Florida: CRC Press. https://doi:10.1017/S1431927611012050

Shan, P. \& Lai, X. 2019. Influence of CT scanning parameters on rock and soil images. Journal of Visual Communication and Image Representation. 58: 642-650. https://doi.org/10.1016/j.jvcir.2018.12.014

Shivhare, S. \& Cecil, K. 2021. Automatic soil classification by using Gabor wavelet \& support vector machine in digital image processing. In 2021 Third International Conference on Inventive Research in Computing Applications (ICIRCA). IEEE. 1738-1743. https://doi.org/10.1109/ICIRCA51532.2021.9544897

Siltas Company. 2018. [accessed: 19 October 2018] Available from: http://www.siltas.com.tr/uretim.php

Srivastava, P., Shukla, A. \& Bansal, A. 2021. A comprehensive review on soil classification using deep learning and computer vision techniques. Multimedia Tools and Applications. 80: 1-28. https://doi.org/10.1007/s11042021-10544-5

Tekin, I., Birgul, R., Yaman, I.O., Gencel, O. \& Aruntas, H.Y. 2015. Monitoring macro voids in mortars by computerized tomography method. Measurement. 63: 299-308. https://doi.org /10.1016/j.measurement.2014.11.034

TS 1900-2. 2006. Methods of testing soils for civil engineering purposes in the laboratory - Part 2: Determination of mechanical properties. Turkish Standard Institute. Ankara, Turkey.

Wang, Y., Zhao, X. \&Wang, B. 2013. LS-SVM and Monte Carlo methods based reliability analysis for settlement of soft clayey foundation. Journal of Rock Mechanics and Geotechnical Engineering. 5(4): 312-317. https://doi.org/10.1016/j.jrmge.2012.06.003

Zhao, Z. \& Zhou, X.P. 2019. Digital measurement of 2D and 3D cracks in sandstones through improved pseudo color image enhancement and 3D reconstruction method. International Journal for Numerical and Analytical Methods in Geomechanics. 43(16): 2565-2584. https://do i.org/10.1002/nag.2993 